\title{
Multicomponent Peptide Hydrogels as an Innovative Platform for Cell-Based Tissue Engineering in the Dental Pulp
}

\author{
Marina E. Afami ${ }^{1}$, Ikhlas El Karim ${ }^{1}$, Imad About ${ }^{2}$, Anna D. Krasnodembskaya ${ }^{1}$, Garry Laverty ${ }^{3}$ \\ and Fionnuala T. Lundy ${ }^{1, *}$ (D) \\ 1 Wellcome-Wolfson Institute for Experimental Medicine, School of Medicine, Dentistry and Biomedical Sciences, \\ Queen's University Belfast, 97 Lisburn Road, Belfast BT9 7BL, UK; mafami01@qub.ac.uk (M.E.A.); \\ i.elkarim@qub.ac.uk (I.E.K.); a.krasnodembskaya@qub.ac.uk (A.D.K.) \\ 2 Aix Marseille Univ, CNRS, ISM, Inst Movement Sci, 13385 Marseille, France; imad.about@univ-amu.fr \\ 3 School of Pharmacy, Queen's University Belfast, 97 Lisburn Road, Belfast BT9 7BL, UK; \\ garry.laverty@qub.ac.uk \\ * Correspondence: f.lundy@qub.ac.uk
}

\section{check for} updates

Citation: Afami, M.E.; El Karim, I. About, I.; Krasnodembskaya, A.D.;

Laverty, G.; Lundy, F.T.

Multicomponent Peptide Hydrogels

as an Innovative Platform for

Cell-Based Tissue Engineering in the Dental Pulp. Pharmaceutics 2021, 13, 1575. https://doi.org/10.3390/ pharmaceutics13101575

Academic Editors: Gregor Fuhrmann and Rita Sobral Santos

Received: 14 August 2021

Accepted: 22 September 2021

Published: 28 September 2021

Publisher's Note: MDPI stays neutral with regard to jurisdictional claims in published maps and institutional affiliations.

Copyright: (c) 2021 by the authors. Licensee MDPI, Basel, Switzerland. This article is an open access article distributed under the terms and conditions of the Creative Commons Attribution (CC BY) license (https:/ / creativecommons.org/licenses/by/ $4.0 /)$.

\begin{abstract}
In light of the increasing levels of antibiotic resistance, nanomaterials and novel biologics are urgently required to manage bacterial infections. To date, commercially available self-assembling peptide hydrogels have not been studied extensively for their ability to inhibit micro-organisms relevant to tissue engineering sites such as dental root canals. In this work, we assess the biocompatibility of dental pulp stem/stromal cells with commercially available multicomponent peptide hydrogels. We also determine the effects of dental pulp stem/stromal cell (DPSC) culture in hydrogels on growth factor/cytokine expression. Furthermore, to investigate novel aspects of self-assembling peptide hydrogels, we determine their antimicrobial activity against the oral pathogens Staphylococcus aureus, Enterococcus faecalis, and Fusobacterium nucleatum. We show that self-assembling peptide hydrogels and hydrogels functionalized with the adhesion motif Arg-Gly-Asp (RGD) are biocompatible with DPSCs, and that cells grown in 3D hydrogel cultures produce a discrete secretome compared with 2D-cultured cells. Furthermore, we show that soluble peptides and assembled hydrogels have antimicrobial effects against oral pathogens. Given their antibacterial activity against oral pathogens, biocompatibility with dental pulp stem/stromal cells and enhancement of an angiogenic secretome, multicomponent peptide hydrogels hold promise for translational use.
\end{abstract}

Keywords: antibacterial; antimicrobial; biocompatibility; biofilm; cytokine; dental pulp; growth factor; hydrogel; oral pathogen; secretome

\section{Introduction}

The oral cavity harbours over 700 distinct microbial species that occupy several niches in the oral cavity, including the hard surfaces of the teeth, and the mucosal surfaces of the gums, cheeks and tongue [1]. The non-shedding surfaces of the teeth facilitate the accumulation of microorganisms in the form of dental plaque, which in the absence of good dietary and oral hygiene habits can lead to the development of dental caries. If left untreated, dental caries will extend through the enamel and dentin layers to reach the dental pulp, causing pain and inflammation. Teeth in which the dental pulp has become infected following ingress of caries would conventionally have been treated by root canal treatment, in which the entire dental pulp is removed. However, there is now much interest in dental pulp regeneration, in which scaffolds/nanomaterials are used to deliver stem cells that are either transplanted (allogenic cells) or attracted to the site (autologous cells). For tissue engineering approaches to be successful, there should be effective eradication of infection from the root canals of the teeth; otherwise, there is a high risk of treatment failure [2]. The requirement for effective disinfection in regenerative procedures is possibly more stringent than with conventional endodontic therapies [2], 
such as standard root canal treatments, which are well known to have a higher risk of failure if disinfection is incomplete. Although many bacterial taxa have been identified in root canals, the current study focuses on three bacteria that have been documented to play particularly important roles in endodontic infection. Enterococcus faecalis has been reported to have a major role in the aetiology of persistent infections and is able to survive in the root canal as a single organism or as a major component of the microbiota [3,4]. Several studies have also detected high rates of the Gram-negative anaerobic rod, Fusobacterium nucleatum, in infected root canals. The presence of $F$. nucleatum has been reported in teeth with both primary infection [5] and persistent endodontic infection [6]. Staphylococcus aureus is another microorganism commonly found in infected root canals [7] and is one of the major causes for the failure of standard root canal treatment [8].

Hydrogels (water-swollen networks of polymers) have emerged as particularly attractive materials for biomedical and dental applications because of their ability to mimic the in vivo extracellular environment in three dimensions [9]. Hydrogels have been shown to support cell adhesion and demonstrate biocompatible properties [9]. Furthermore, they can be specifically designed to have mechanical properties resembling those of tissues in vivo. Despite the urgent need for novel biologics to manage bacterial infections in the oral cavity and other bodily sites, much remains to be learned about the development of hydrogels with novel antimicrobial properties. Amongst the many classes of hydrogels in current use (containing synthetic polymers or natural polymers), peptide hydrogels are a promising class. Their chemical versatility, providing a vast choice of chemical functional groups, enables tailoring of the peptide primary sequence to required functional properties (e.g., mechanical properties, syringeability) for specific application.

Peptides are ubiquitous in nature, and the sequence of their amino acids specifically determines their biological functions, including their propensity to be antimicrobial [10]. Peptide hydrogels that self-assemble are often categorised as hybrid hydrogels, as they retain the biocompatibility of naturally derived extracellular matrix molecules, but are synthesised using standard peptide synthesis techniques [11]. Peptide hydrogels bridge the gap between the use of naturally occurring molecules and chemically synthesised molecules as hydrogel polymers. Self-assembling peptide hydrogels are thus smart/designer novel biologics with a wide range of potential therapeutic applications. Amongst their key attributes such as their biocompatibility and ease of synthesis, antimicrobial activity is emerging as a clinically relevant novel characteristic that is worthy of exploitation for the management of bacterial infections. Indeed, animal models have shown that residual bacteria limit tissue mineralization in regenerative endodontic procedures [12]. Although hydrogels are used experimentally in regenerative endodontics, the majority of current research is focused on the development of hydrogels that are biocompatible with cells in the local environment. Whilst this is of course an essential attribute for hydrogels designed for tissue engineering purposes, it is only one factor that contributes to the development of a successful novel biologic. Our research group is interested in the application of biocompatible hydrogels with inherent antimicrobial characteristics for use in tissue engineering [13] in the oral cavity. We previously demonstrated the antibacterial properties associated with 'in-house' ultra-short peptide hydrogels $[13,14]$ specifically designed to exhibit antimicrobial activity against oral pathogens [13], and now seek to address the possibility that commercially available multicomponent peptide hydrogels may also exhibit this favourable characteristic.

Peptide hydrogels functionalized with the cell adhesion motif arginine-glycine-aspartic acid (RGD) have the components necessary to promote self-assembly, along with the cell adhesive properties of RGD, which is well documented as a recognition site and anchor for cell adhesion [15]. Indeed, recent work has shown that the RGD motif enhances cell-matrix interactions and promotes cell survival/proliferation [16] in functionalized hyaluroic acid hydrogels. Further investigations are needed to determine the role of RGD in multicomponent hydrogels and expedite their translation to clinical use. We therefore hypothesised that commercially available multicomponent peptide hydrogels (+/ - RGD adhesion motifs) may have unrecognised antimicrobial activity, as this characteristic of peptide hydrogels 
has generally not been tested, except for hydrogels specifically designed for this purpose. There have been no previous reports on the influence of the RGD motif on antimicrobial activity, but given its important role in cellular adhesion and survival/proliferation, we sought to determine whether it influenced antimicrobial activity in multicomponent hydrogels. Herein, we studied commercially available peptide hydrogels and custom synthesised RGD-containing peptide hydrogels, with a view to demonstrating their biocompatibility with dental pulp cells, their influence on the secretome of dental pulp cells and their propensity for antimicrobial activity against the oral pathogens E. faecalis, F. nucleatum and S. aureus.

\section{Materials and Methods}

\subsection{Peptide Hydrogels}

Peptide hydrogels (Biogelx ${ }^{\mathrm{TM}}-\mathrm{S}$ or Biogelx ${ }^{\mathrm{TM}}-\mathrm{RGD}$ ) were manufactured by Biogelx (Newhouse, Scotland). The Biogelx ${ }^{\mathrm{TM}}$-S formulation, containing 50\% 9-fluorenylmethoxycarbonyl -diphenylalanine (Fmoc-FF) and 50\% 9-fluorenylmethoxycarbonyl-serine (Fmoc-S), is a standard hydrogel formulation without adhesion motifs, and is subsequently referred to as $0 \%$ RGD. The RGD containing peptide hydrogels (Biogelx ${ }^{\mathrm{TM}}-\mathrm{RGD}$ ) also contained 9-fluorenylmethoxycarbonyl-RGD (Fmoc-RGD) and were custom synthesised (Biogelx, Newhouse, Scotland) with various percentages of RGD-functionalized peptides $(10 \%, 25 \%, 40 \%, 50 \%$ RGD), as detailed in Table 1 . All peptides were assembled in hydrogel form as described by the manufacturer. Briefly, the weight of the powder dissolved in water was adjusted according to desired gel volume and stiffness. All assembled hydrogels in this study were prepared at concentrations of $4.4-5.4 \mathrm{mg} / \mathrm{mL}$, according to the manufacturer's instructions. These concentrations of peptides were described by the manufacturer to exhibit rigidity within the range of $0.8-1.1 \mathrm{kPa}$, when assembled in hydrogel form. The solution of peptides in water was stored overnight at $4{ }^{\circ} \mathrm{C}$ to allow stabilization of the fibres, prior to the initiation of gelation the following day, upon addition of cell culture media. Peptides in assembled hydrogel form were utilised in modified 3-(4,5-dimethylthiazol-2-yl)2,5-diphenyltetrazolium bromide (MTT) assays [17], cell encapsulation studies, secretome studies and bacterial susceptibility assays. In addition, peptides in their soluble form were investigated for their biocompatibility with a sub-population of dental mesenchymal stem cells, which were positive for the mesenchymal marker, stromal precursor antigen 1 (Stro-1). Peptides in solution form were also tested for their antibiofilm properties. Peptides were maintained in solution form by dissolving the peptides in culture media containing $0.005 \%$ DMSO (Sigma-Aldrich, Dorset, UK).

Table 1. Composition of standard Biogelx hydrogel (Biogelx-S) ( $0 \%$ RGD) and custom synthesized RGD-containing hydrogels.

\begin{tabular}{cccc}
\hline \multirow{2}{*}{ Hydrogel } & \multicolumn{3}{c}{ Components (\% moles) } \\
\cline { 2 - 4 } & Fmoc-FF (\%) & Fmoc-S (\%) & Fmoc-RGD (\%) \\
\hline 0\% RGD & 50 & 50 & 0 \\
10\% RGD & 50 & 40 & 10 \\
25\% RGD & 50 & 25 & 25 \\
40\% RGD & 50 & 10 & 40 \\
$50 \%$ RGD & 50 & 0 & 50 \\
\hline
\end{tabular}

\subsection{Explant Culture of Dental Pulp Cells}

Samples of human dental pulp tissue [18] were obtained in accordance with French ethics legislation and approved by the Office for Research Ethics Committees (Northern Ireland) ethical approval number $08 / \mathrm{NIR} 03 / 15$, dated $11 / 04 / 08$. The dental pulp tissue was cut into small fragments using a sharp scalpel and cultured using the previously described explant method [19]. Cells were cultured in $\alpha$-MEM (Thermo Fisher Scientific, Waltham, MA, USA), supplemented with $10 \%$ heat inactivated foetal bovine serum 
(Thermo Fisher Scientific, Waltham, MA, USA), 1\% $w / v$ L-glutamine (L-glut) (Thermo Fisher Scientific, Waltham, MA, USA) and $1 \% w / v$ penicillin + streptomycin (Thermo Fisher Scientific, Waltham, MA, USA). Dental pulp cells, often collectively referred to as dental pulp stem/stromal cells (DPSCs), were grown at $37^{\circ} \mathrm{C}$ with $5 \% \mathrm{CO}_{2}$, to a confluence of approximately $80 \%$. Cells of passages $2-4$ were used throughout all experiments.

\subsection{Biocompatibility Screening of Peptides in $2 D$ Culture}

The cytotoxicity of a series of multicomponent peptide hydrogels $(0 \%, 10 \%, 25 \%, 40 \%$ and 50\% RGD) was initially screened in their soluble forms against a population of Stro-1positive DPSCs using a standard MTT assay. In the absence of a technique that results in a perfectly homogenous population of mesenchymal stem cells [20], Stro-1 is often used as a marker of multipotent mesenchymal progenitor cells in the dental pulp. Stro-1-positive cells were obtained as previously described by us using immunomagentic sorting [21]. The Stro-1-positive DPSCs $\left(100 \mu \mathrm{L} ; 1 \times 10^{4}\right.$ cells $\left./ \mathrm{mL}\right)$ were transferred to each well of a flat-bottomed 96-well microtitre plate (Nunclon Delta Surface, Thermo Fisher Scientific, Waltham, MA, USA) and incubated for $48 \mathrm{~h}$ at $37{ }^{\circ} \mathrm{C}$ in a humidified atmosphere of $5 \% \mathrm{CO}_{2}$. After $48 \mathrm{~h}$ incubation, the medium was aspirated from the wells and replaced with $100 \mu \mathrm{L}$ of liquid peptides at concentrations of $0.01 \%$ and $0.1 \% w / v$ for 24 or $72 \mathrm{~h}$. When hydrogels are formed, it is recognised that small proportions of the peptides may not incorporate into the gel but instead diffuse into the solution [14]. As a result, soluble peptides may be present on the surface of the hydrogel. Greater than $0.44 \% w / v$ peptide concentrations were required for gelation to occur in all five $(0 \%, 10 \%, 25 \%, 40 \%$ or $50 \%$ RGD) hydrogels tested (according to the manufacturer's instructions). We therefore prepared $0.1 \% w / v$ and $0.01 \%$ $w / v$ solutions of soluble peptides (as outlined in Section 2.1) to determine their potential cytotoxicity at two different concentrations below the critical gelation concentration for each hydrogel. This was undertaken in order to test the potential cell cytotoxicity of material extracts in line with International Standard (ISO 10993-5) methods for biomaterials. In addition to treating cells with $0.1 \% w / v$ and $0.01 \% w / v$ peptides, the control wells contained $100 \mu \mathrm{L}$ of media per well in place of the soluble peptides. After 24 or $72 \mathrm{~h}, 10 \mu \mathrm{L}$ of MTT ( $5 \mathrm{mg} / \mathrm{mL}$ in HBSS) (Sigma-Aldrich, Dorset, UK) was added to the wells [22] and incubated for $3 \mathrm{~h}$. Following this, the medium was removed and the wells were allowed to air dry for $10 \mathrm{~min}$. Formazan crystals, representing mitochondrial activity, were dissolved in $200 \mu \mathrm{L}$ DMSO (Sigma-Aldrich, Dorset, UK) and the absorbance was measured at $510 \mathrm{~nm}$ using a plate reader (Genios Spectrophotometer). Stro-1-positive DPSCs were employed only for initial screening purposes, and mixed population DPSCs (subsequently referred to as DPSCs) were studied in the remaining experiments.

\subsection{DPSC Encapsulation in Assembled Hydrogels}

DPSCs $\left(1 \times 10^{6}\right.$ cells $\left./ \mathrm{mL}\right)$ were encapsulated in multicomponent peptide hydrogels containing $0 \%, 10 \%, 25 \%, 40 \%$ and 50\% RGD $(100 \mu \mathrm{L}$ of cells were encapsulated in $100 \mu \mathrm{L}$ of hydrogel) and plated in glass bottom dishes (WillCo Wells BV, Amsterdam, The Netherlands). Before plating the encapsulated cells, an area on the bottom of each dish was marked with a hydrophobic barrier pen (Fisher Scientific, Dublin, Ireland) to ensure that the hydrogels were retained within a defined area. Then, $200 \mu \mathrm{L} \alpha$-MEM was gently added on top, and the cells were incubated in the 3D hydrogel construct for $24 \mathrm{~h}$. Cells were then fixed in $4 \%$ paraformaldehyde for $30 \mathrm{~min}$ and washed three times with phosphate buffered saline (PBS) before adding several drops of ProLong ${ }^{\text {TM }}$ Gold Antifade Mountant with 4',6-diamidino-2phenylindole (DAPI; ThermoFisher Scientific, Warrington, UK). The hydrogel construct was then cured at room temperature for $24 \mathrm{~h}$ prior to the visualisation of encapsulated cells by SP8 Confocal Microscopy (Leica, Wetzlar, Germany). Z stack images were acquired and processed using LAS X software (Leica Microsystems, Wetzlar, Germany). 


\subsection{Biocompatibility of Assembled Hydrogels with DPSCs in 3D Culture}

DPSCs $\left(1 \times 10^{6}\right.$ cells $\left./ \mathrm{mL}\right)$ were encapsulated in hydrogels $(0 \%, 10 \%, 25 \%, 40 \%$ and $50 \%$ RGD) and cultured in $200 \mu \mathrm{L} \alpha$-MEM as outlined above. A modified MTT assay for 3 D culture was employed to determine DPSC viability [23]. Cells cultured in $2 \% w / v$ hydroxypropyl methylcellulose (HPMC) hydrogels were used as controls. The viability of DPSCs was determined at 1 and 14 days following cell encapsulation. Briefly, $20 \mu \mathrm{L}$ of MTT ( $5 \mathrm{mg} / \mathrm{mL}$ in Hanks balanced salt solution) was added to each well and incubated for $1 \mathrm{~h}$ at $37^{\circ} \mathrm{C}$. The cell medium $(200 \mu \mathrm{L})$ was then carefully removed and replaced with DMSO $(200 \mu \mathrm{L})$ and incubated at $37^{\circ} \mathrm{C}$ for $10 \mathrm{~min}$. The blue MTT-formazan product was then eluted by shaking the plate at $220 \mathrm{rpm}$ for $3 \mathrm{~h}$. Following dye elution, the supernatant from each well was transferred to a new plate and the absorbance measured at $570 \mathrm{~nm}$ on a microplate reader (Thermo Scientific Varioskan LUX, Warrington, UK) using SkanIt RE 4.1 software.

\subsection{Antibacterial Activity Assays}

The antibacterial activities of $0 \%$ RGD and 10\% RGD peptides in both solution and assembled hydrogel form were tested. The antibacterial effects of low concentrations $(0.01 \%$ and $0.1 \% w / v$ ) of peptides in solution (representing soluble peptides that may diffuse from the hydrogel surface $[14,24]$ ) were tested against bacterial biofilms in 96-well microtitre plates. Prior to establishing biofilms, S. aureus (ATCC 25923) and E. faecalis (NCTC 12697) were grown aerobically in Müeller-Hinton broth and the broth was allowed to reach midLogarithmic phase $(6 \mathrm{~h})$, before dilution to $1 \times 10^{6}$ colony forming units $(\mathrm{CFU}) / \mathrm{mL}$ in Müeller-Hinton broth to obtain the desired inoculums for the biofilm assay. The inoculums (100 $\mu \mathrm{L}$ per well) were incubated aerobically for $5 \mathrm{~h}$ to establish initial S. aureus and E. faecalis biofilms. F. nucleatum (NCTC 10562) was grown anaerobically in fastidious anaerobe broth (LabM Limited, Lancashire, UK). On reaching the mid-logarithmic phase $\left(15 \mathrm{~h}\right.$ ), it was diluted to $5 \times 10^{6} \mathrm{CFU} / \mathrm{mL}$ in anaerobic broth to obtain the desired inoculum for the biofilm assay. Wells containing $100 \mu \mathrm{L}$ of inoculum were incubated anaerobically for $48 \mathrm{~h}$ to establish initial F. nucleatum biofilms.

Following the establishment of initial biofilms, planktonic bacteria were removed by carefully washing with PBS, and the biofilms were treated with $100 \mu \mathrm{L}$ of $0 \%$ RGD or $10 \%$ RGD in solution form at concentrations of $0.01 \%$ and $0.1 \% w / v$. Control wells for each micro-organism were treated with the vehicle only (broth containing $0.005 \% \mathrm{DMSO}$ ). Following treatment, biofilms were allowed to mature either aerobically for a further $24 \mathrm{~h}$ (S. aureus and E. faecalis) or anaerobically for a further $48 \mathrm{~h}$ (F. nucleatum). After incubation for either 24 or $48 \mathrm{~h}$, planktonic bacteria were removed by washing and the biofilm biomass was quantified by the crystal violet assay [25].

To test whether the assembled hydrogels had antibacterial activity, bacterial viability was determined by the colony count method [26]. Briefly, inoculums of S. aureus and E. faecalis $\left(2 \times 10^{6} \mathrm{CFU} / \mathrm{mL}\right)$ or F. nucleatum $\left(5 \times 10^{6} \mathrm{CFU} / \mathrm{mL}\right)$ were prepared as outlined above. Bacterial suspensions $(100 \mu \mathrm{L})$ were seeded on top of $100 \mu \mathrm{L} 0 \%$ RGD or $10 \%$ RGD assembled hydrogels in 96-well plates. Bacterial suspensions $(100 \mu \mathrm{L})$ served as untreated control wells. After incubation for $24 \mathrm{~h}$, a sample of the bacterial suspension $(20 \mu \mathrm{L})$ was removed from each well and serially diluted. A total volume of $10 \mu \mathrm{L}$ from each dilution was plated out on appropriate agar plates for viability counting. The results were displayed as mean $\log _{10} \mathrm{CFU} / \mathrm{mL}$.

\subsection{Human Growth Factor/Cytokine Array}

Human growth factor/cytokine array membranes were purchased from Abcam (Cambridge UK) for the detection and semi-quantification of 43 growth factors/cytokines in the secretome of DPSCs following 2D or 3D culture. Conditioned medium was collected on day 14 , and the assay procedure was performed as described in the manufacturer's instructions. The arrays were imaged using a Syngene G: BOX, with GeneSys software and semiquantified using ImageJ, an image analysis programme, with a microarray plugin. For 
each array membrane, the integrated density of the spots was measured and then the mean integrated density of negative controls was subtracted for background correction. To ensure that array results could be compared across the various experimental conditions (2D versus $0 \%$ RGD or $10 \%$ RGD), the $2 \mathrm{D}$ array was designated as the reference array membrane. The positive control spots on the $2 \mathrm{D}$ reference array were then used to normalise the signal intensity (integrated density) on the 0\% RGD and 10\% RGD membranes. The normalised integrated density for each growth factor/cytokine on any given array was calculated using the formula:

$$
X(N y)=X(y) \times P 1 / P(y)
$$

where: $X(N y)=$ Normalized signal density for spot " $X$ " on array " $y$ "

$X(y)=$ Signal density for spot " $X$ " on array " $y$ "

$P 1=$ Mean signal density of positive control spots on reference array (2D array)

$P(y)=$ Mean signal density of positive control spots on array " $y$ " (0\% RGD or 10\% RGD arrays).

\subsection{Statistical Analysis}

All results were expressed as the mean of three independent experiments with three to six replicates per experiment. Statistical analysis was undertaken using GraphPad Prism Software (Version 8; GraphPad Software Inc., San Diego, CA, USA). Data that passed the Shapiro-Wilk or D'agostino and Pearson test were analysed by means of one-way ANOVA followed by Dunnett's post hoc correction for multiple comparisons. Otherwise, data were analysed non-parametrically by means of a Kruskal-Wallis test with Dunn's correction for multiple comparison testing, as indicated in the figure legends. The level of statistical significance was set at $p<0.05$.

\section{Results}

3.1. Biocompatibility of Soluble Peptides and Assembled Hydrogels (+/- RGD Functionalization) with DPSCs

The biocompatibility of the hydrogel peptides in solution form were initially screened against a sub-population of Stro-1-positive DPSCs using standard 2D MTT assays. The results show that for $0.01 \% w / v$ peptides in solution form, only the $40 \%$ and $50 \%$ RGD hydrogel peptides significantly enhanced cellular metabolic activity at $24 \mathrm{~h}$, as measured by the MTT assay (Figure 1A). At $72 \mathrm{~h}$, no significant differences from untreated controls were observed (Figure $1 \mathrm{~A})$. When higher concentrations $(0.1 \% w / v)$ of the peptides were tested in solution form, all peptide hydrogels showed significantly enhanced metabolic activity over controls at $24 \mathrm{~h}$. No significant differences were observed after $72 \mathrm{~h}$ treatment, although the $0 \%$ and 10\% RGD hydrogel peptide treatments remained higher than the controls (Figure 1B).

Having established biocompatibility with a sub-population of Stro-1-positive DPSCs, we then encapsulated the unsorted population of DPSCs in 3D hydrogels and showed by confocal microscopy (Figure 2) that they were maintained in 3D within all the hydrogels, following encapsulation. We also determined the biocompatibility of DPSCs with assembled hydrogels using a 3D MTT assay and showed that the 40 and 50\% RGD peptides significantly enhanced cellular metabolic activity after 1 day (Figure 4A), but no significant differences from untreated controls were observed after 14 days in hydrogel culture (Figure 4B). Since biocompatibility over an extended time period is important for potential regenerative therapeutics, the 10\% RGD peptide hydrogels were selected for further study, on the basis of their superior (although non-significant) biocompatibility at $72 \mathrm{~h}$ (Figure 1B). 
A

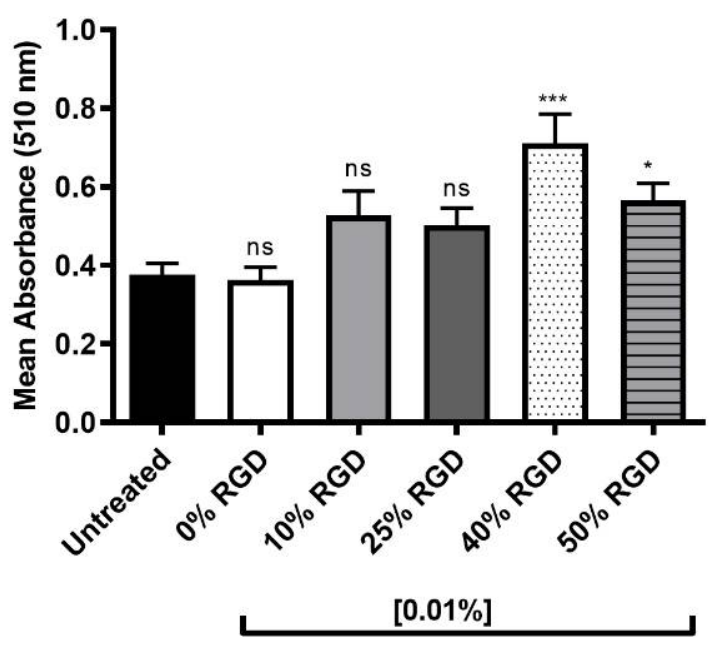

B

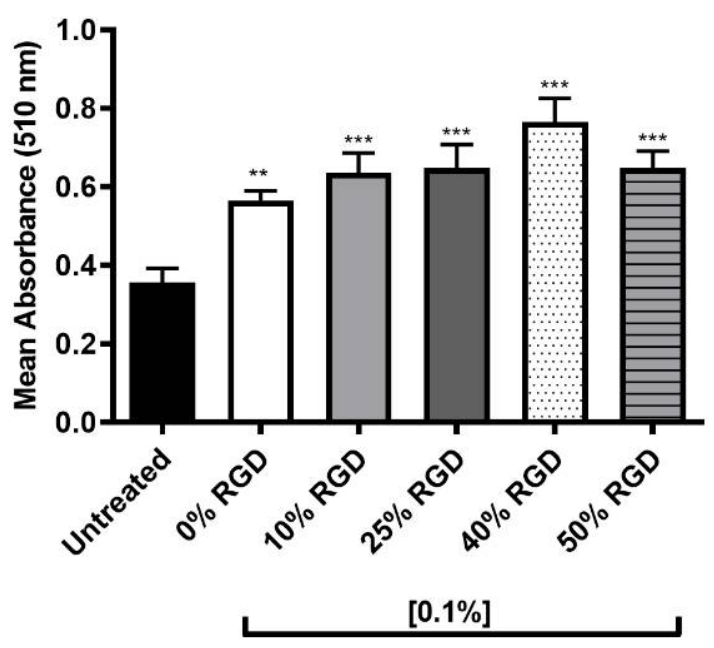

$72 \mathrm{~h}$ incubation

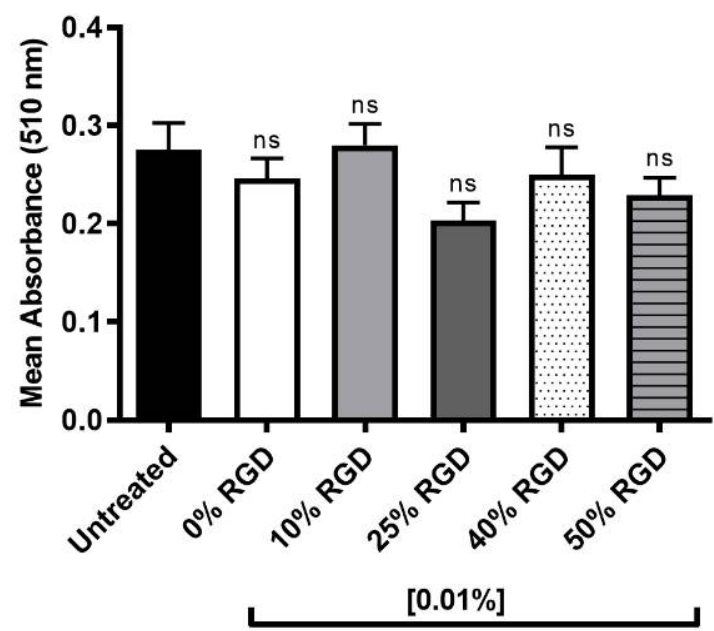

$72 \mathrm{~h}$ incubation

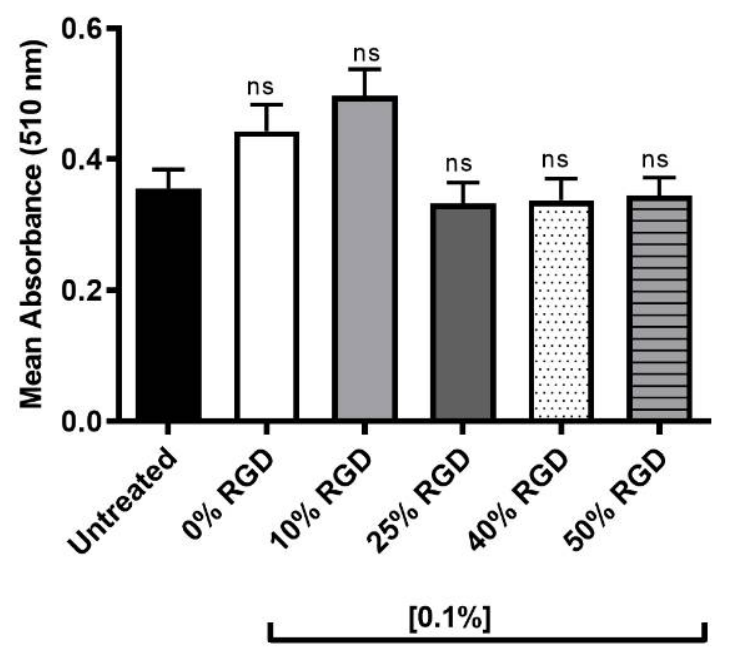

Figure 1. Biocompatibility studies of Stro-1 DPSCs with 0.01 and $0.1 \% w / v$ soluble forms of multicomponent peptides (0-50\% RGD), as determined by the MTT assay. (A) Treatment of Stro-1 DPSCs with peptide concentrations of $0.01 \% w / v$ for 24 and $72 \mathrm{~h}$. (B) Treatment of Stro-1 DPSCs with peptide concentrations of $0.1 \% \mathrm{w} / \mathrm{v}$ for 24 and $72 \mathrm{~h}$. All comparisons were made with the untreated control. Data are from three experiments, with at least three replicates per experiment. Kruskal-Wallis test with Dunn's correction for multiple comparison testing. ns: non-significant; $(p>0.05),{ }^{*}: p \leq 0.05$, ${ }^{* *}: p \leq 0.01{ }^{* * *}: p \leq 0.001$.

\subsection{Secretome of DPSCs in $2 D$ versus $3 D$ Culture}

A total of 43 growth factors and cytokines were measured in the conditioned media from DPSCs grown in a standard 2D culture versus a 3D hydrogel culture $(0 \%$ RGD or $10 \%$ RGD) using an angiogenic array. In the 2D culture, growth-regulated alpha protein (GRO- $\alpha$ ), interleukin-6 (IL-6), IL-8 and monocyte chemoattractant protein-1 (MCP-1) were detected most intensely (Figure $4 \mathrm{~A})$. However, in the 3D culture ( $0 \%$ or $10 \%$ RGD hydrogel), GRO- $\alpha$ and MCP- 1 were not as abundant, and IL- 6 and IL- 8 were barely detectable. On the contrary, a number of growth factors and cytokines, such as angiogenin (ANG), epidermal growth factor (EGF), epithelial neutrophil-activating peptide 78 (ENA-78), platelet-derived 
growth factor BB (PDGF-BB) and vascular endothelial growth factor- D (VEGF-D), were detectable in the 3D culture ( $0 \%$ RGD and 10\% RGD) (Figure $4 B, C)$. Interestingly, there was some variability in growth factors and cytokine expression, depending on the presence or absence of RGD. For example, PDGF-BB levels were higher in the $\%$ RGD versus $10 \%$ RGD culture, and thrombopoietin (THPO) was not detectable in the 10\% RGD culture at all. On the other hand, VEGF-D levels were higher in the $10 \%$ RGD versus $0 \%$ RGD culture (Figure 4B,C).
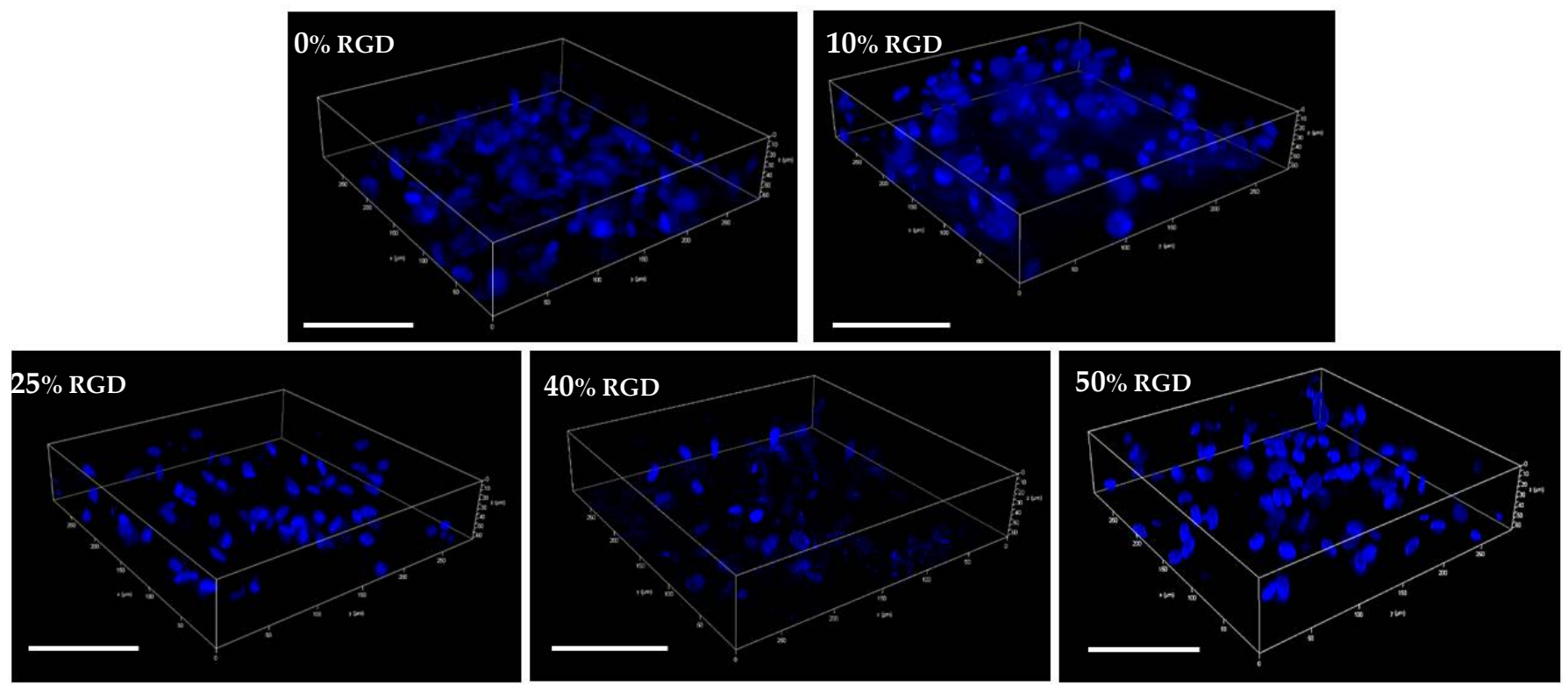

Figure 2. Confocal microscopy of encapsulated DPSCs $(24 \mathrm{~h})$ in $0 \%$ to $50 \%$ RGD hydrogels. Images show that cells were retained in 3D within all hydrogels. Cells were fixed and permeabilised within the hydrogel before staining of the nuclei of encapsulated DPSCs with DAPI. Images were captured using an SP8 Confocal Microscope. Scale bar: $100 \mu \mathrm{m}$.

A

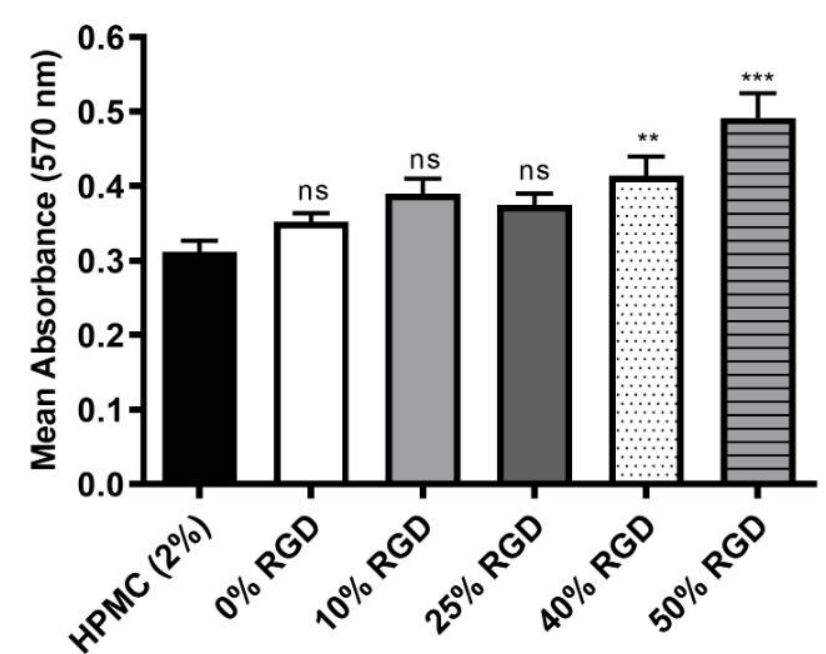

B

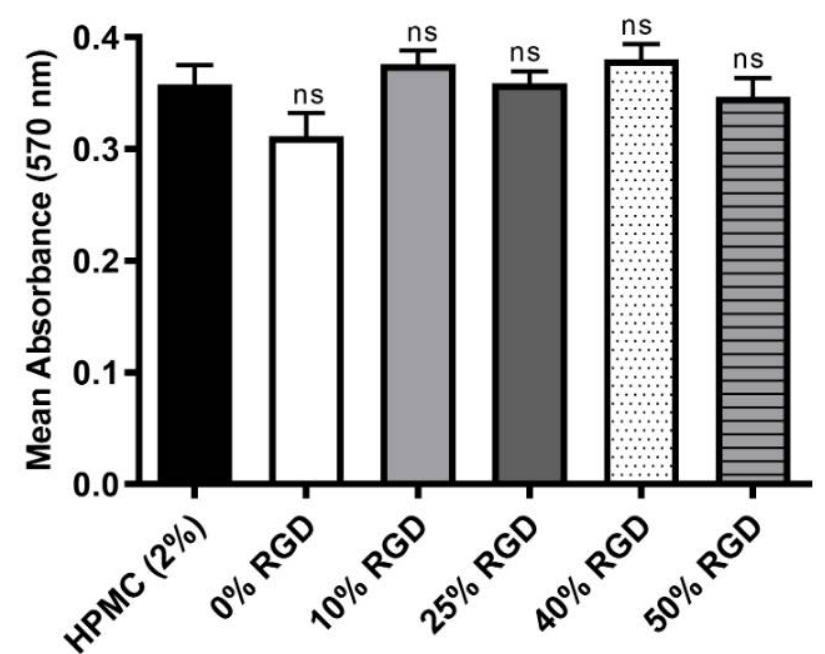

Figure 3. Modified MTT assay (for 3D culture) following encapsulation of DPSCs in HPMC hydrogel and 0-50\% RGD assembled hydrogels at (A) day 1 and (B) day 14. All comparisons were made with the HPMC control. Data are from three experiments, with at least three replicates per experiment. Kruskal-Wallis test with Dunn's correction for multiple comparison testing. ns: non-significant $(p>0.05),{ }^{* *}: p \leq 0.01,{ }^{* * *}: p \leq 0.001$. 


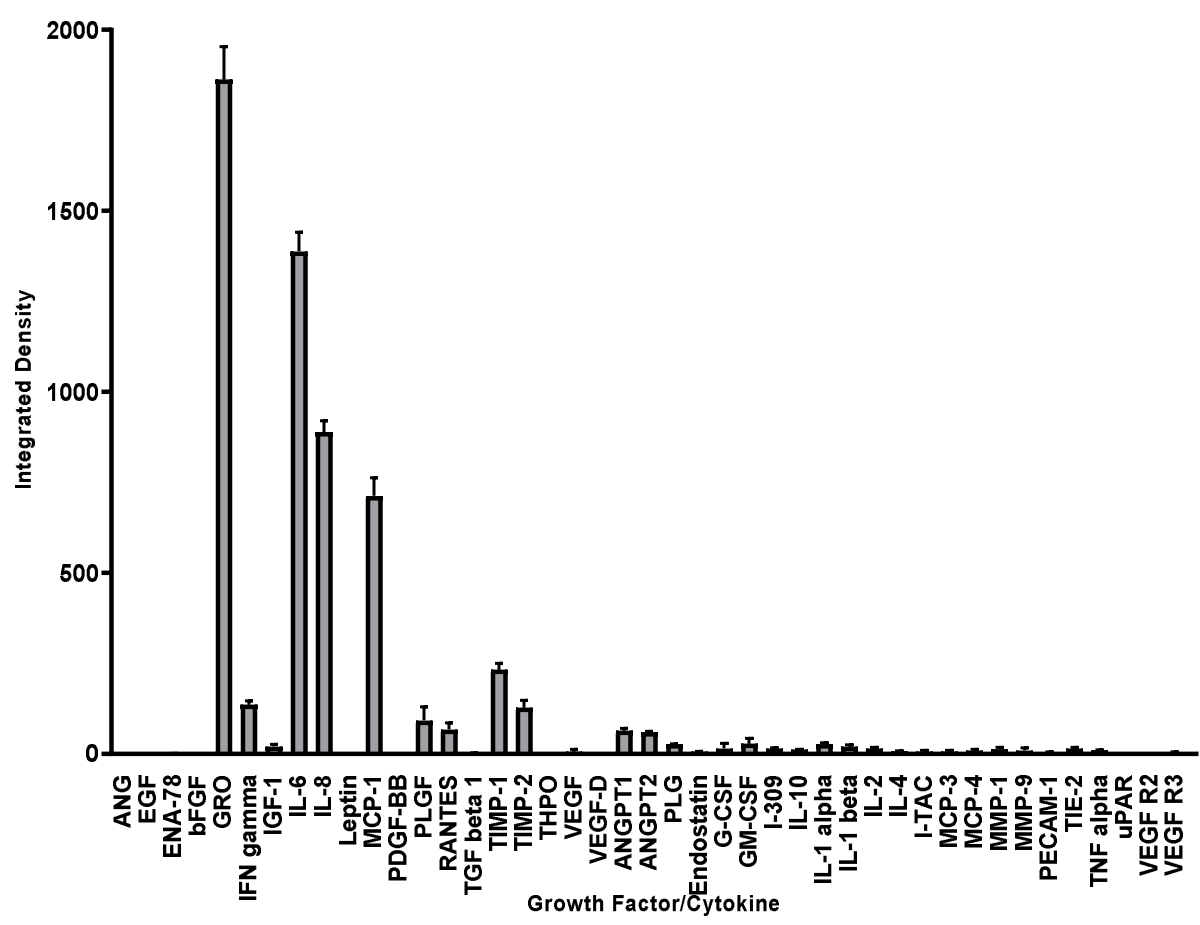

(A)

0\% RGD

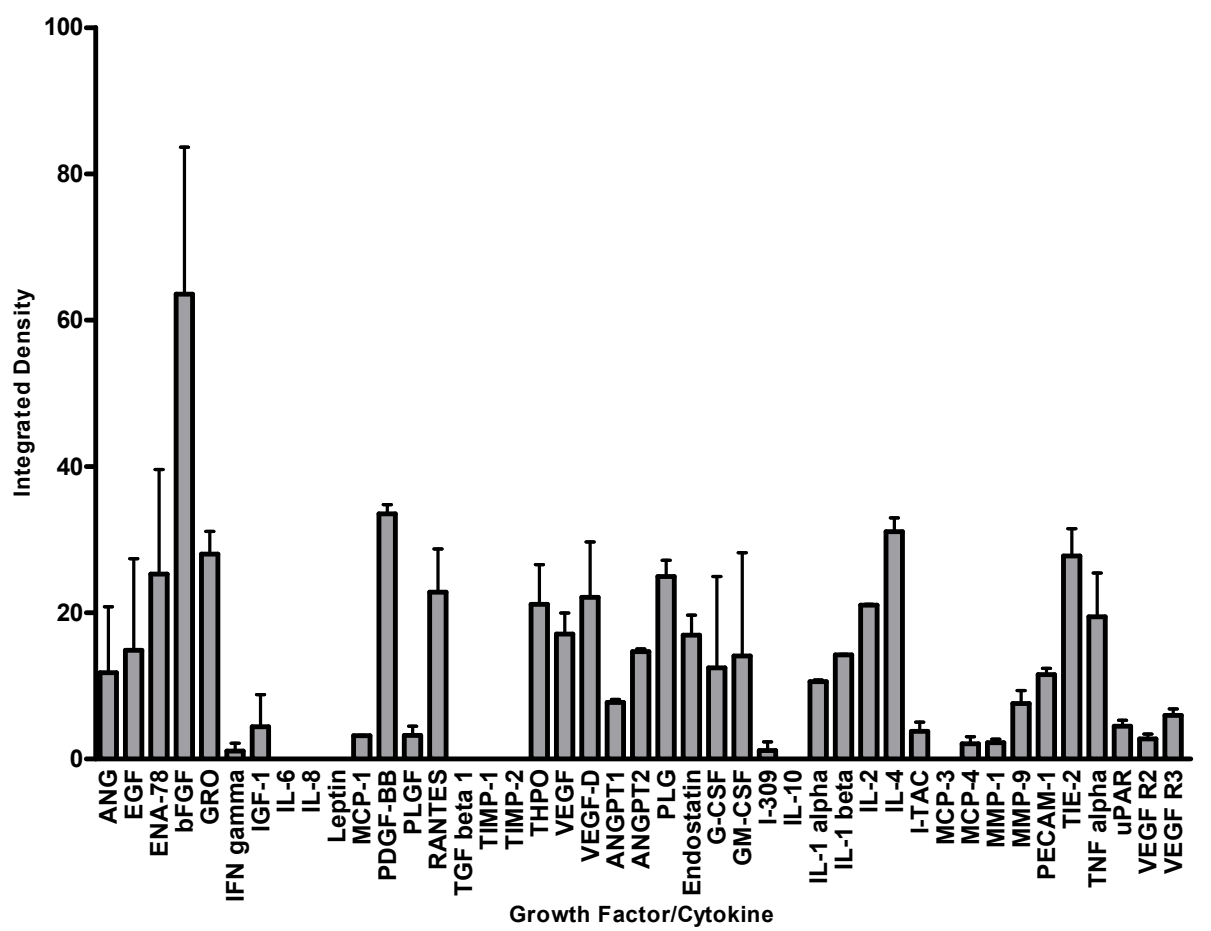

(B)

Figure 4. Cont. 


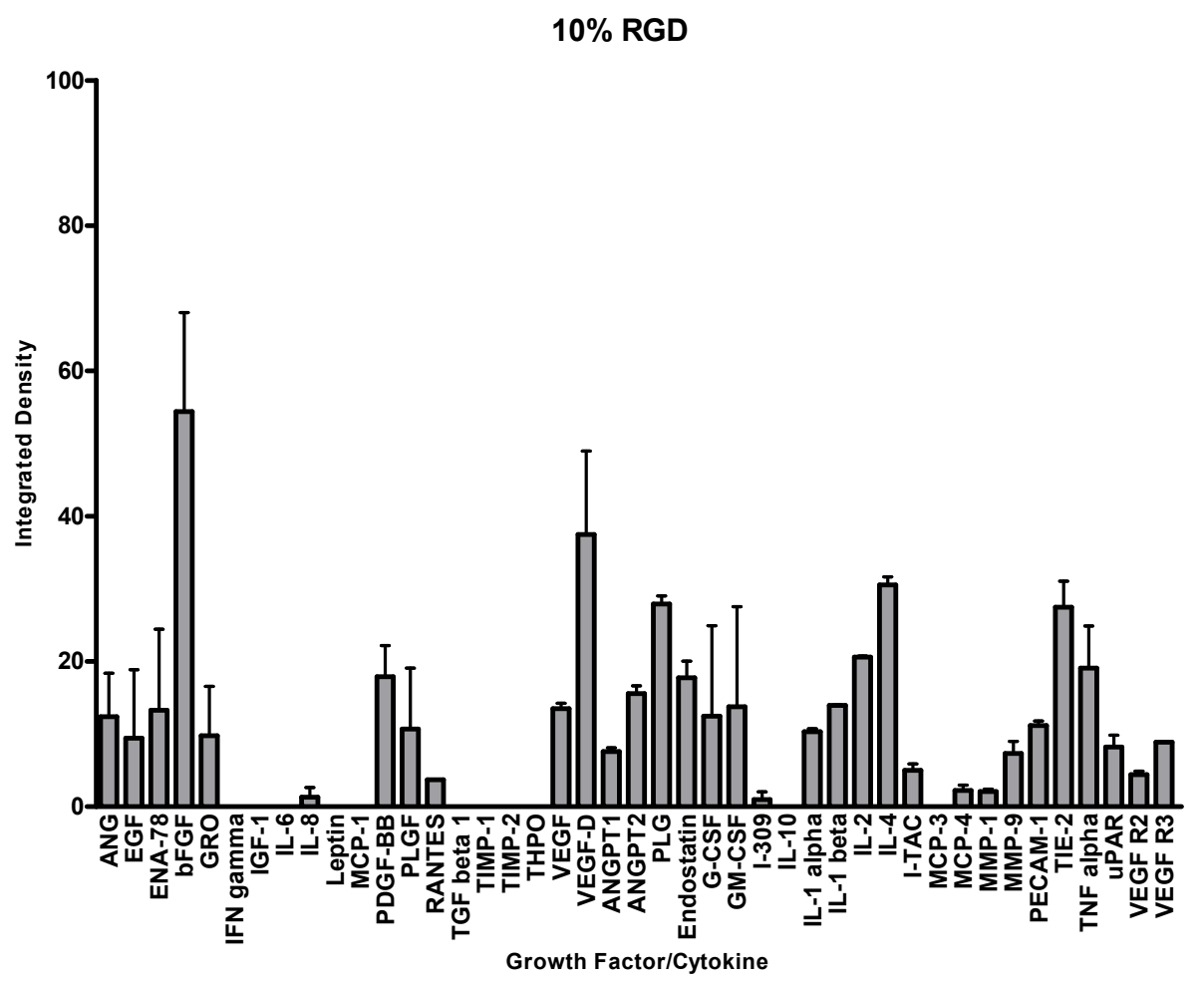

(C)

Figure 4. Growth factors/cytokine expression in conditioned media from DPSCs in (A) 2D culture or following 14-day encapsulation in (B) $0 \%$ RGD or (C) 10\% RGD hydrogels. Abbreviations: angiogenin (ANG); epidermal growth factor (EGF); epithelial neutrophil-activating peptide 78 (ENA-78); basic fibroblast growth factor (bFGF); growth-regulated alpha protein (GRO- $\alpha$ ); interferon gamma (IFN- $\gamma)$; insulin-like growth factor 1 (IGF-1); interleukin-6 (IL-6); interleukin-8 (IL-8); leptin; monocyte chemoattractant protein-1 (MCP-1); platelet-derived growth factor BB (PGDF-BB); placental growth factor (PLGF); regulated upon activation normal T cell expressed and secreted (RANTES); transforming growth factorbeta 1 (TGF- $\beta 1$ ); tissue inhibitor of matrix metalloproteinases-1 (TIMP-1); tissue inhibitor of matrix metalloproteinases-2 (TIMP-2); thrombopoietin (THPO); vascular endothelial growth factor (VEGF); vascular endothelial growth factor- D (VEGF-D); angiopoietin-1 (ANGPT1); angiopoietin-2 (ANGPT2); plasminogen (PLG); endostatin; granulocyte colony stimulating factor (G-CSF); granulocyte-macrophage colony-stimulating factor (GM-CSF); T lymphocyte-secreted protein I-309 (I-309); interleukin-10 (IL-10); interleukin-1 alpha (IL-1 $\alpha$ ); interleukin-1 beta (IL-1 $\beta$ ); interleukin-2 (IL-2); interleukin-4 (IL-4); interferon-inducible T cell alpha chemoattractant (I-TAC); monocyte chemoattractant protein-3 (MCP-3); monocyte chemoattractant protein-4 (MCP-4); matrix metalloproteinase-1 (MMP-1); matrix metalloproteinase-9 (MMP-9); platelet and endothelial cell adhesion molecule-1 (PECAM-1); tyrosine kinase with immunoglobulin-like and EGF-like domains (TIE-2); tumour necrosis factor alpha (TNF $\alpha)$; urokinase plasminogen activator surface receptor (uPAR); vascular endothelial growth factor receptor 2 (VEGF R2); vascular endothelial growth factor receptor 3 (VEGF R3).

\subsection{Antibacterial Properties of Soluble Peptides and Assembled Peptide Hydrogels}

In order to investigate the antibacterial properties of the peptide hydrogels (+ / - RGD), it was important to determine whether low concentrations of the peptides (representing soluble peptides that could potentially diffuse from the hydrogel surface) had antibacterial activity against biofilms of oral pathogens. There was a significant reduction in the biomass of $S$. aureus biofilms following treatment with the $0 \%$ RGD and 10\% RGD peptides at a concentration of $0.01 \% w / v$, but not at a concentration of $0.1 \% w / v$ (Figure $5 \mathrm{~A}$ ). The biofilm biomass of $E$. faecalis biofilms was significantly reduced following treatment with the $0 \%$ RGD and $10 \%$ RGD peptides, at both concentrations tested $(0.01 \%$ and $0.1 \% w / v)$. When F. nucleatum biofilms were treated, only the 0\% RGD hydrogel peptides were shown to significantly reduce biofilm biomass at a concentration of $0.1 \% w / v$ (Figure 5 C). 
S. aureus (ATCC 25923)

A

$0.01 \%$
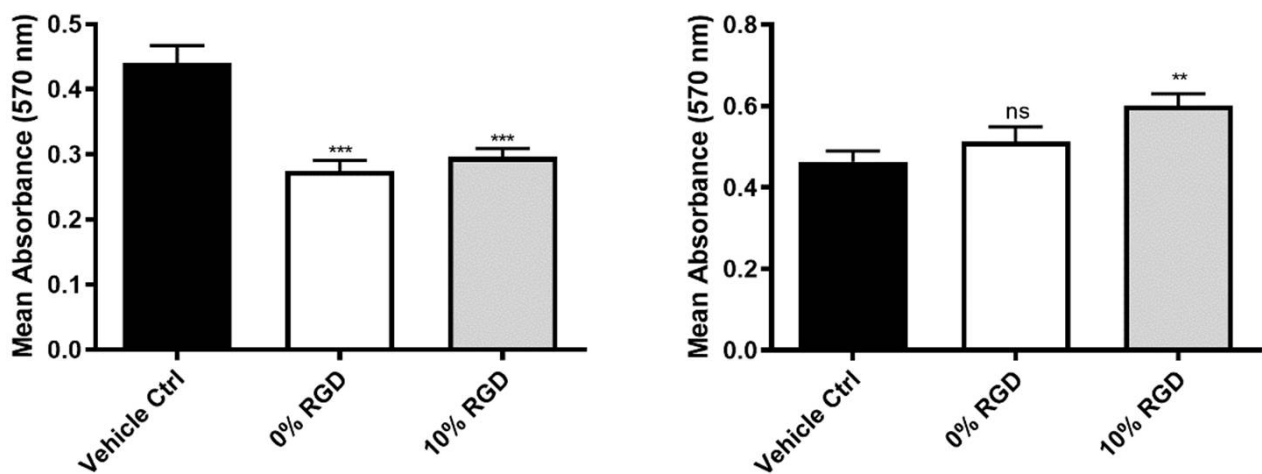

E. faecalis (NCTC 12697)

B

$0.01 \%$
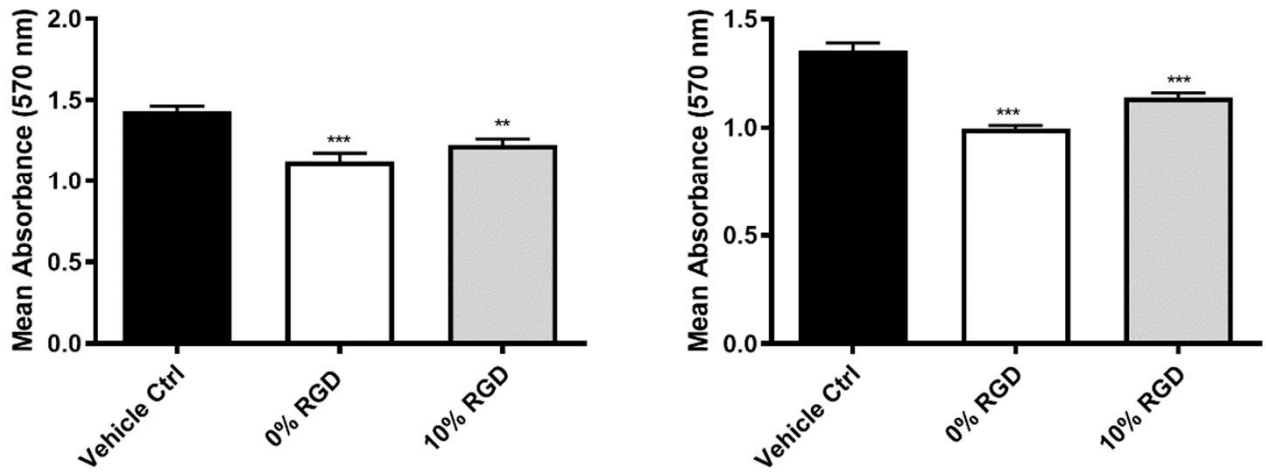

F. nucleatum (NCTC 10562)

C

$0.01 \%$

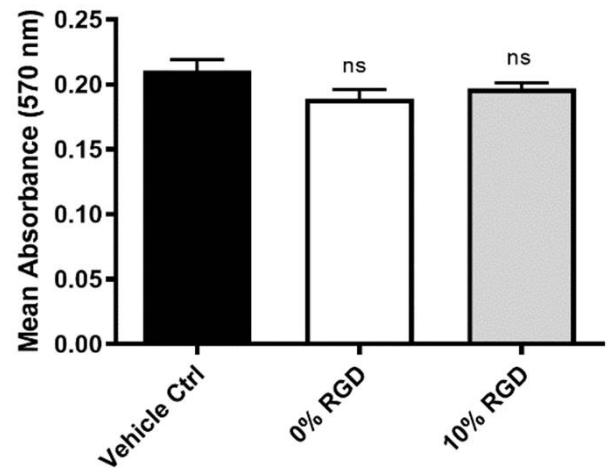

$0.1 \%$

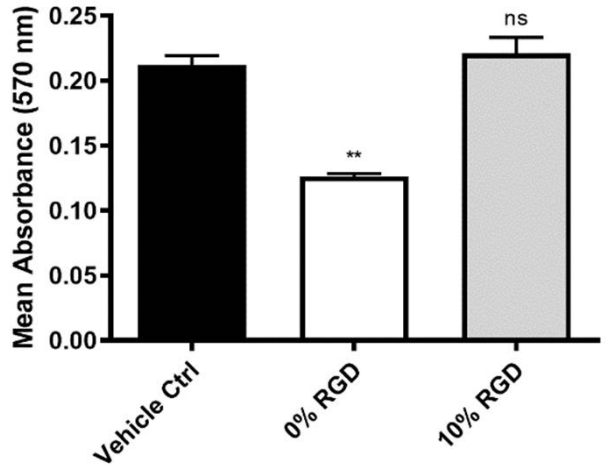

Figure 5. Biofilm inhibition by $0 \%$ RGD and 10\% RGD soluble peptides, as determined by the crystal violet assay. (A) S. aureus, (B) E. faecalis and (C) F. nucleatum biofilm biomass following $24 \mathrm{~h}$ incubation with $0.01 \%$ and $0.01 \% w / v$ peptides. All comparisons were made with vehicle controls. Data are from three experiments, with at least three replicates per experiment. S. aureus and E. faecalis data analysed by one-way ANOVA with Dunnett's correction for multiple comparison testing. F. nucleatum data analysed by a Kruskal-Wallis test with Dunn's correction for multiple comparison testing. ns: non-significant $(p>0.05),{ }^{* *}: p \leq 0.01,{ }^{* * *}: p \leq 0.001$. 
The antibacterial activity of the assembled hydrogels was then tested against S. aureus, E. faecalis and F. nucleatum, using a CFU viable count assay. After $24 \mathrm{~h}$ bacterial growth on the hydrogel surface, there was no significant change in the number of CFU of $S$. aureus or E. faecalis, but F. nucleatum numbers were significantly reduced by the $10 \%$ RGD assembled hydrogel (Figure 6).
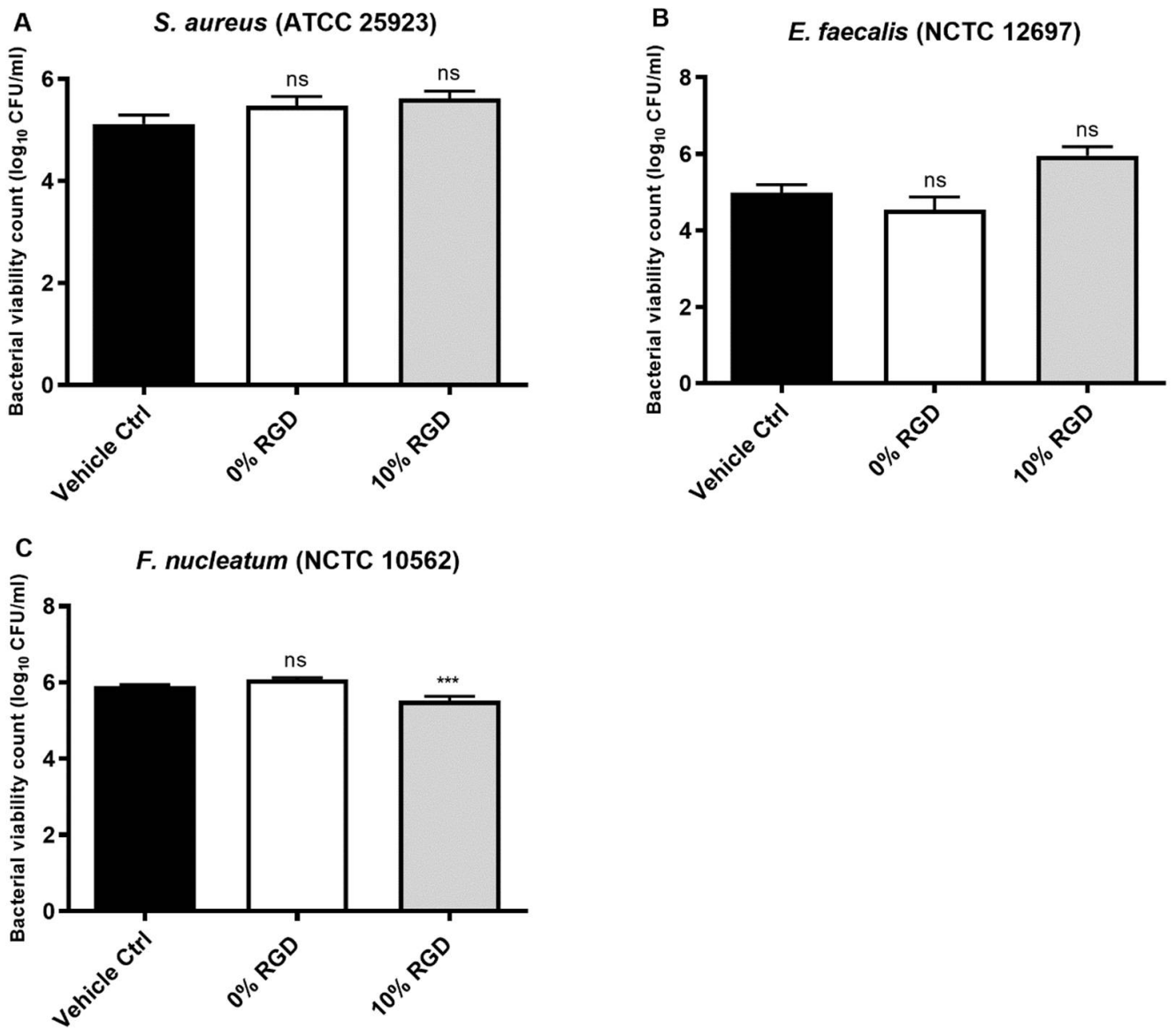

Figure 6. Bacterial viability counts $\left(\log _{10} \mathrm{CFU} / \mathrm{mL}\right)$ following $24 \mathrm{~h}$ growth on the surface of $0 \% \mathrm{RGD}$ or $10 \%$ RGD assembled hydrogels. (A) S. aureus, (B) E. faecalis and (C) F. nucleatum. All comparisons were made with untreated controls. Data are from three experiments, with at least three replicates per experiment. S. aureus and F. nucleatum data analysed by one-way ANOVA with Dunnett's correction for multiple comparison testing. E. faecalis data analysed by a Kruskal-Wallis test with Dunn's correction for multiple comparison testing. ns: non-significant $(p>0.05),{ }^{* * *}: p \leq 0.001$.

\section{Discussion}

In the development of hydrogels that are biocompatible with a variety of human stem/stromal cell types, a popular approach has been to employ functional fragments of ECM proteins, including the cell adhesion motif RGD [27]. Whilst the majority of studies focus on the biocompatibility [28] or cell attachment properties of RGD, some researchers have also investigated the addition of nanoparticles to RGD-containing hydrogels to generate novel antimicrobial properties [29]. In the current study, we examined the biocompatibility of peptide hydrogels synthesised without ( $0 \%$ ) or with (10-50\%) of the RGD cell adhesion motif. We also investigated the angiogenic secretome of DPSCs cultured in $2 \mathrm{D}$ versus $0 \%$ or $10 \%$ RGD in 3D hydrogel culture. In addition, we investigated the antimicrobial properties of the peptide hydrogels ( $\% \%$ and $10 \%$ RGD) against three oral pathogens.

Our results show that the hydrogels were biocompatible with both Stro-1-positive DPSCs and unsorted DPSCs. Stro- 1 sorting of DPSCs is often undertaken to select a 
sub-population of DPSCs of mesenchymal origin, with the propensity for odontogenic differentiation [30]. The 10\% RGD hydrogel showed more favourable biocompatibility at $72 \mathrm{~h}$ against Stro-1-positive cells. However, if hydrogels are to be translated for therapeutic use, then it is also important that their biocompatibility against unsorted DPSCs is studied in 3D cultures. Using confocal microscopy, we showed that all the hydrogels tested were capable of retaining DPSCs in 3D, and also that all hydrogels displayed similar biocompatibilities with DPSCs after 14 days in 3D culture. It is worth noting that we used encapsulated cells for 3D culture, since cells are often grown on top of flat hydrogels/hydrogel surfaces as simplified methods for biocompatibility studies [27,31].

The selection of the 10\% RGD hydrogel, over higher \% RGD hydrogels for further study, is in line with previous work, which suggests that too many RGD anchors may hinder cellular activity within the scaffold [32]. The hydrogels used in this study contained a homogenous mixture of 10\% RGD functionalized peptides and $90 \%$ non-RGD peptides. Previous work has shown that there are subtle differences between hydrogels containing homogenous RGD versus clustered RGD. Clustering of RGD has been reported to facilitate cell spreading/elongation within the hydrogel [32,33], but may not have the initial cell adhesion characteristics of homogenous RGD [32].

With a view to determining the effect of 3D hydrogel culture on the DPSC secretome, we investigated angiogenic growth factor/cytokine release from DPSCs in 2D versus 3D ( $0 \%$ or $10 \%$ RGD) hydrogel culture. The release of angiogenic factors plays an important role in repair and regeneration in the dental pulp, and thus the synthesis and release of such factors from cells within the hydrogel could provide the microenvironment needed for angiogenesis, as an alternative to supplementation by exogenous angiogenic factors $[34,35]$. Analysis of the DPSC secretome showed that culture in 3D resulted in the decreased expression of pro-inflammatory factors such as IL-6 and IL-8, along with an increase in the expression of pro-angiogenic factors such as ANG, EGF, ENA-78, PDGF-BB, and VEGF-D. When $0 \%$ RGD and 10\% RGD 3D hydrogel cultures were compared, some factors showed decreased levels in 10\% RGD (PDGF-BB and THPO), whereas VEGF-D levels were higher in the $10 \%$ RGD versus $0 \%$ RGD culture. Interestingly, it has previously been hypothesised that RGD hydrogels activate the $\alpha \mathrm{v} \beta 3$ integrin on cells to cause heightened sensitivity to the presence of VEGF within the microenvironment [36]. This effect, together with the increased levels of VEGF in 10\% RGD hydrogels, could enhance angiogenesis.

Hydrogels are currently being designed to incorporate functional antimicrobial components; examples include the incorporation of silver moieties [29] or antibiotics [37] (reviewed in [38]). However, although many peptides have inherent antimicrobial activity, peptide hydrogels have not conventionally been assessed for their inherent antimicrobial effects. We initially tested the antibiofilm effects of low concentrations of soluble peptide components of the hydrogels, as it has previously been debated that antimicrobial activity is not exclusive to the process of gelation and that the presence of soluble peptides around the hydrogel surface could also have a role in determining antimicrobial efficacy [14,24]. Thus, peptides in soluble form may be present on the hydrogel surface $[13,14,24]$ and could contribute to antimicrobial activity. Solutions of $0.01 \% w / v$ peptides $(0 \%$ RGD and $10 \%$ RGD) were effective against S. aureus and E. faecalis biofilms. A $0.1 \% w / v$ solution of $0 \%$ RGD was required for efficacy against $F$. nucleatum, but the 10\% RGD culture had no significant antibiofilm effect. The exact mechanisms of action of the peptides in solution on the hydrogel surface have not been investigated, but it is likely that they cause membrane disruption in a similar manner to that reported for naturally occurring antimicrobial peptides [39]. Many antimicrobial peptides achieve their antimicrobial effects by disrupting the bacterial lipid bilayer, leading to the leakage of cell contents and ultimately bacterial cell death [40]. The efficacy of various antimicrobial peptides against different bacteria has been reported to depend on the membrane lipid composition [40]. Hence, the selectivity of antimicrobial peptides against the different bacterial strains studied in the present work could be attributed to differences in bacterial membrane lipid composition [41]. It has also been reported that additional protection against antimicrobials is offered by the outer 
membrane of Gram-negative bacteria [42]. The presence of the outer membrane could contribute to the tendency of F. nucleatum, particularly in biofilm form, to be more resistant to treatment with $0.01 \% \mathrm{w} / \mathrm{v}$ soluble peptides, as observed in the current study. It is important to note that the antibiofilm activity is not only related to the ability of the peptide to interact with and disrupt the bacterial membrane, but also on its ability to penetrate the biofilm matrix [43]. Biofilms are widely recognised to be recalcitrant to treatment with antibiotics [44] or antimicrobial peptides [45], emphasising the need for further work in this research field [46].

In addition to investigating the antimicrobial activity of soluble peptides, we also investigated whether the assembled hydrogels had antimicrobial properties [47]. It is worth noting that the peptides in solution displaying anti-biofilm efficacy did not directly translate to antibacterial efficacy in assembled hydrogel form, as determined by the CFU assay and vice versa. There are numerous factors that could contribute to this apparent disparity. The process of self-assembly has previously been reported to influence antimicrobial properties [47]. It is thought that a combination of factors, including changes in secondary structure and charge distribution, particularly the surface charge and the ratio of charge to surface area, will occur in peptide assembly, thereby influencing peptidebacterial interactions [47]. It was interesting to note that one assembled hydrogel, namely 10\% RGD, displayed antimicrobial activity, but only against F. nucleatum. Since the RGD motif contains one positively charged amino acid (R), one uncharged amino acid (G) and one negatively charged amino acid (D), it is unlikely that RGD incorporation affected the overall charge of the $10 \%$ RGD versus the $0 \%$ RGD peptide hydrogel. However, as discussed above, it is possible that self-assembly of the peptides may have altered the charge distribution in the assembled hydrogel, facilitating antimicrobial efficacy that was not observed with the soluble peptides. Comparisons of the efficacies of the soluble and assembled hydrogel forms of the peptides are, however, difficult, because their antimicrobial activities were tested against biofilms, or bacteria seeded on the hydrogel surface, respectively. Moreover, it is likely that both the soluble and assembled hydrogel forms could contribute to antimicrobial activity in vivo. Thus, any reduction in bacterial burden by hydrogel components, combined with the host immune response, could contribute to successful resolution of infection.

In conclusion, peptide hydrogels (+/ - RGD) are biocompatible with DPSCs and have antibacterial activity against oral pathogens. In addition, the hydrogels were shown to influence the secretome of encapsulated cells. Replicating the subtle concentration gradients and temporal changes of exogenously applied growth factors for tissue engineering purposes is a complex process, associated with significant regulatory issues. However, the ability to engineer hydrogel scaffolds so that the cells encapsulated within them produce their own growth factors, as well as exhibiting inherent antibacterial and biocompatible characteristics, could greatly improve their clinical efficacy.

Author Contributions: Conceptualization, I.E.K., I.A., A.D.K., G.L. and F.T.L.; formal analysis, M.E.A.; investigation, M.E.A.; resources, I.E.K., I.A., G.L. and F.T.L.; validation, M.E.A.; visualization, M.E.A. and F.T.L.; supervision, I.E.K., G.L. and F.T.L.; project administration, I.E.K. and F.T.L.; funding acquisition, M.E.A., I.E.K., A.D.K., G.L. and F.T.L.; Writing—original draft, M.E.A. and F.T.L.; Writing-review and editing, M.E.A., I.E.K., I.A., A.D.K., G.L. and F.T.L. All authors have read and agreed to the published version of the manuscript.

Funding: This research was funded by an MRC Proximity to Discovery grant. M.E.A. was supported by a PhD Studentship from the Department for the Economy (Northern Ireland) and by the A.G. Leventis Foundation.

Institutional Review Board Statement: The study was conducted according to the guidelines of the Declaration of Helsinki, and approved by the Office for Research Ethics Committees (Northern Ireland) ethical approval number 08/NIR03/15, dated 11/04/08.

Informed Consent Statement: Informed consent was obtained from all subjects involved in the study.

Data Availability Statement: Data are available from the corresponding author upon reasonable request. 
Acknowledgments: The authors gratefully acknowledge the skilful technical assistance of Catherine Fulton.

Conflicts of Interest: The authors declare no conflict of interest. The funders had no role in the design of the study; in the collection, analyses, or interpretation of data; in the writing of the manuscript, or in the decision to publish the results.

\section{References}

1. Gao, L.; Xu, T.; Huang, G.; Jiang, S.; Gu, Y.; Chen, F. Oral microbiomes: More and more importance in oral cavity and whole body. Protein Cell 2018, 9, 488-500. [CrossRef] [PubMed]

2. Fouad, A.F. The Microbial Challenge to Pulp Regeneration. Adv. Dent. Res. 2011, 23, 285-289. [CrossRef] [PubMed]

3. Evans, M.; Davies, J.K.; Sundqvist, G.; Figdor, D. Mechanisms involved in the resistance of Enterococcus faecalis to calcium hydroxide. Int. Endod. J. 2002, 35, 221-228. [CrossRef] [PubMed]

4. Stuart, C.H.; Schwartz, S.A.; Beeson, T.J.; Owatz, C.B. Enterococcus faecalis: Its Role in Root Canal Treatment Failure and Current Concepts in Retreatment. J. Endod. 2006, 32, 93-98. [CrossRef]

5. Rôças, I.N.; Alves, F.R.F.; Santos, A.L.; Rosado, A.S.; Siqueira, J.F. Apical root canal microbiota as determined by re-verse-capture checkerboard analysis of cryogenically ground root samples from teeth with apical periodontitis. J. Endod. 2010, 36, 1617-1621. [CrossRef]

6. Zhang, C.; Hou, B.-X.; Zhao, H.-Y.; Sun, Z. Microbial diversity in failed endodontic root-filled teeth. Chin. Med. J. 2012, 125, 1163-1168.

7. Siqueira, J.F.; de Uzeda, M. Intracanal medicaments: Evaluation of the antibacterial effects of chlorhexidine, metronidazole, and calcium hydroxide associated with three vehicles. J. Endod. 1997, 23, 167-169. [CrossRef]

8. de Gomes, B.P.F.A.; Pedroso, J.L.; Jacinto, R.; Vianna, M.E.; Ferraz, C.; Zaia, A.A.; De Souza-Filho, F.J. In vitro evaluation of the antimicrobial activity of five root canal sealers. Braz. Dent. J. 2004, 15, 30-35. [CrossRef]

9. Tibbitt, M.W.; Anseth, K.S. Hydrogels as extracellular matrix mimics for 3D cell culture. Biotechnol. Bioeng. 2009, 103, 655-663. [CrossRef]

10. Schmitt, P.; Rosa, R.D.; Destoumieux-Garzón, D. An intimate link between antimicrobial peptide sequence diversity and binding to essential components of bacterial membranes. Biochim. Biophys. Acta Biomembr. 2016, 1858, 958-970. [CrossRef]

11. Li, J.; Xing, R.; Bai, S.; Yan, X. Recent advances of self-assembling peptide-based hydrogels for biomedical applications. Soft Matter. 2019, 15, 1704-1715. [CrossRef] [PubMed]

12. Verma, P.; Nosrat, A.; Kim, J.; Price, J.; Wang, P.; Bair, E.; Xu, H.; Fouad, A. Effect of Residual Bacteria on the Outcome of Pulp Regeneration In Vivo. J. Dent. Res. 2016, 96, 100-106. [CrossRef] [PubMed]

13. Afami, M.; El Karim, I.; About, I.; Coulter, S.; Laverty, G.; Lundy, F. Ultrashort Peptide Hydrogels Display Antimicrobial Activity and Enhance Angiogenic Growth Factor Release by Dental Pulp Stem/Stromal Cells. Materials 2021, 14, 2237. [CrossRef]

14. Laverty, G.; McCloskey, A.; Gilmore, B.F.; Jones, D.S.; Zhou, J.; Xu, B. Ultrashort Cationic Naphthalene-Derived Self-Assembled Peptides as Antimicrobial Nanomaterials. Biomacromolecules 2014, 15, 3429-3439. [CrossRef]

15. Lutolf, M.P.; Hubbell, J.A. Synthetic biomaterials as instructive extracellular microenvironments for morphogenesis in tissue engineering. Nat. Biotechnol. 2005, 23, 47-55. [CrossRef]

16. Teng, B.; Zhang, S.; Pan, J.; Zeng, Z.; Chen, Y.; Hei, Y.; Fu, X.; Li, Q.; Ma, M.; Sui, Y.; et al. A chondrogenesis induction system based on a functionalized hyaluronic acid hydrogel sequentially promoting hMSC proliferation, condensation, differentiation, and matrix deposition. Acta Biomater. 2021, 122, 145-159. [CrossRef]

17. Widbiller, M.; Lindner, S.; Buchalla, W.; Eidt, A.; Hiller, K.-A.; Schmalz, G.H.; Galler, K.M. Three-dimensional culture of dental pulp stem cells in direct contact to tricalcium silicate cements. Clin. Oral Investig. 2015, 20, 237-246. [CrossRef]

18. About, I.; Bottero, M.-J.; de Denato, P.; Camps, J.; Franquin, J.-C.; Mitsiadis, T. Human Dentin Production in Vitro. Exp. Cell Res. 2000, 258, 33-41. [CrossRef] [PubMed]

19. Hilkens, P.; Gervois, P.; Fanton, Y.; Vanormelingen, J.; Martens, W.; Struys, T.; Politis, C.; Lambrichts, I.; Bronckaers, A. Effect of isolation methodology on stem cell properties and multilineage differentiation potential of human dental pulp stem cells. Cell. Tissue Res. 2013, 353, 65-78. [CrossRef]

20. Waddington, R.J.; Youde, S.J.; Lee, C.P.; Sloan, A. Isolation of Distinct Progenitor Stem Cell Populations from Dental Pulp. Cells Tissues Organs 2008, 189, 268-274. [CrossRef] [PubMed]

21. Winning, L.; El Karim, I.; Lundy, F.T. A Comparative Analysis of the Osteogenic Potential of Dental Mesenchymal Stem Cells. Stem Cells Dev. 2019, 28, 1050-1058. [CrossRef]

22. McLean, D.T.; McCrudden, M.T.; Linden, G.; Irwin, C.R.; Conlon, J.M.; Lundy, F.T. Antimicrobial and immunomodulatory properties of PGLa-AM1, CPF-AM1, and magainin-AM1: Potent activity against oral pathogens. Regul. Pept. 2014, 194-195, 63-68. [CrossRef] [PubMed]

23. Galler, K.M.; Brandl, F.P.; Kirchhof, S.; Widbiller, M.; Eidt, A.; Buchalla, W.; Göpferich, A.; Schmalz, G. Suitability of Different Natural and Synthetic Biomaterials for Dental Pulp Tissue Engineering. Tissue Eng. Part A 2018, 24, 234-244. [CrossRef]

24. Salick, D.A.; Kretsinger, J.K.; Pochan, D.J.; Schneider, J.P. Inherent antibacterial activity of a peptide-based beta-hairpin hydrogel. J. Am. Chem. Soc. 2007, 129, 14793-14799. [CrossRef] [PubMed]

25. Stepanović, S.; Vuković, D.; Dakić, I.; Savić, B.; Švabić-Vlahović, M. A modified microtiter-plate test for quantification of staphylococcal biofilm formation. J. Microbiol. Methods 2000, 40, 175-179. [CrossRef] 
26. McCloskey, A.P.; Gilmore, S.M.; Zhou, J.; Draper, E.R.; Porter, S.; Gilmore, B.F.; Xu, B.; Laverty, G. Self-assembling ultrashort NSAID-peptide nanosponges: Multifunctional antimicrobial and anti-inflammatory materials. RSC Adv. 2016, 6, 114738-114749. [CrossRef]

27. Dumbleton, J.; Agarwal, P.; Huang, H.; Hogrebe, N.; Han, R.; Gooch, K.J.; He, X. The effect of RGD peptide on 2D and miniaturized 3D culture of HEPM cells, MSCs, and ADSCs with alginate hydrogel. Cell. Mol. Bioeng. 2016, 9, 277-288. [CrossRef]

28. Aye, S.-S.S.; Li, R.; Boyd-Moss, M.; Long, B.; Pavuluri, S.; Bruggeman, K.; Wang, Y.; Barrow, C.R.; Nisbet, D.R.; Williams, R.J. Scaffolds Formed via the Non-Equilibrium Supramolecular Assembly of the Synergistic ECM Peptides RGD and PHSRN Demonstrate Improved Cell Attachment in 3D. Polymers 2018, 10, 690. [CrossRef]

29. Diniz, I.M.A.; Chen, C.; Ansari, S.; Zadeh, H.; Moshaverinia, M.; Chee, D.; Marques, M.; Shi, S.; Moshaverinia, A. Gingival Mesenchymal Stem Cell (GMSC) Delivery System Based on RGD-Coupled Alginate Hydrogel with Antimicrobial Properties: A Novel Treatment Modality for Peri-Implantitis. J. Prosthodont. 2015, 25, 105-115. [CrossRef]

30. Yang, X.; van den Dolder, J.; Walboomers, X.F.; Zhang, W.; Bian, Z.; Fan, M.; Jansen, J.A. The odontogenic potential of STRO-1 sorted rat dental pulp stem cells in vitro. J. Tissue Eng. Regen. Med. 2007, 1, 66-73. [CrossRef]

31. Ouyang, L.; Dan, Y.; Shao, Z.; Yang, S.; Yang, C.; Liu, G.; Duan, D. MMP-sensitive PEG hydrogel modified with RGD promotes bFGF, VEGF and EPC-mediated angiogenesis. Exp. Ther. Med. 2019, 18, 2933-2941. [CrossRef] [PubMed]

32. Wang, Z.; Zhu, X.; Zhang, R. Characterization and Analysis of Collective Cellular Behaviors in 3D Dextran Hydrogels with Homogenous and Clustered RGD Compositions. Materials 2019, 12, 3391. [CrossRef] [PubMed]

33. Lam, J.; Segura, T. The modulation of MSC integrin expression by RGD presentation. Biomaterials 2013, 34, 3938-3947. [CrossRef] [PubMed]

34. Yamaguchi, N.; Zhang, L.; Chae, B.-S.; Palla, C.S.; Furst, E.; Kiick, K.L. Growth Factor Mediated Assembly of Cell ReceptorResponsive Hydrogels. J. Am. Chem. Soc. 2007, 129, 3040-3041. [CrossRef]

35. Tengood, J.E.; Ridenour, R.; Brodsky, R.; Russell, A.; Little, S.R. Sequential Delivery of Basic Fibroblast Growth Factor and Platelet-Derived Growth Factor for Angiogenesis. Tissue Eng. Part A 2011, 17, 1181-1189. [CrossRef]

36. García, J.R.; Clark, A.Y.; García, A.J. Integrin-specific hydrogels functionalized with VEGF for vascularization and bone regeneration of critical-size bone defects. J. Biomed. Mater. Res. Part A 2015, 104, 889-900. [CrossRef] [PubMed]

37. Das, D.; Das, R.; Ghosh, P.; Dhara, S.; Panda, A.B.; Pal, S. Dextrin cross linked with poly(HEMA): A novel hydrogel for colon specific delivery of ornidazole. RSC Adv. 2013, 3, 25340-25350. [CrossRef]

38. Veiga, A.S.; Schneider, J.P. Antimicrobial hydrogels for the treatment of infection. Biopolymers 2013, 100, 637-644. [CrossRef]

39. Shai, Y. Mechanism of the binding, insertion and destabilization of phospholipid bilayer membranes by $\alpha$-helical antimicrobial and cell non-selective membrane-lytic peptides. Biochim. Biophys. Acta Biomembr. 1999, 1462, 55-70. [CrossRef]

40. Bechinger, B.; Gorr, S.-U. Antimicrobial Peptides: Mechanisms of Action and Resistance. J. Dent. Res. 2016, 96, 254-260. [CrossRef]

41. Cheng, J.T.; Hale, J.D.; Elliott, M.; Hancock, R.E.; Straus, S.K. The importance of bacterial membrane composition in the structure and function of aurein 2.2 and selected variants. Biochim. Biophys. Acta Biomembr. 2011, 1808, 622-633. [CrossRef]

42. Epand, R.M.; Walker, C.; Epand, R.F.; Magarvey, N.A. Molecular mechanisms of membrane targeting antibiotics. Biochim. Biophys. Acta Biomembr. 2016, 1858, 980-987. [CrossRef] [PubMed]

43. Mai, S.; Mauger, M.T.; Niu, L.-N.; Barnes, J.B.; Kao, S.; Bergeron, B.E.; Ling, J.-Q.; Tay, F.R. Potential applications of antimicrobial peptides and their mimics in combating caries and pulpal infections. Acta Biomater. 2017, 49, 16-35. [CrossRef]

44. Petchiappan, A.; Chatterji, D. Antibiotic Resistance: Current Perspectives. ACS Omega 2017, 2, 7400-7409. [CrossRef] [PubMed]

45. Batoni, G.; Maisetta, G.; Esin, S. Antimicrobial peptides and their interaction with biofilms of medically relevant bacteria. Biochim. Biophys. Acta Biomembr. 2016, 1858, 1044-1060. [CrossRef] [PubMed]

46. Khan, J.; Tarar, S.M.; Gul, I.; Nawaz, U.; Arshad, M. Challenges of antibiotic resistance biofilms and potential combating strategies: A review. 3 Biotech 2021, 11, 1-15. [CrossRef]

47. Chen, L.; Liang, J.F. Peptide Fibrils with Altered Stability, Activity, And Cell Selectivity. Biomacromolecules 2013, 14, $2326-2331$. [CrossRef] [PubMed] 